\title{
Role of Preoperative Embolization for Hypervascular Cherubism
}

\author{
Soumil Singhal ${ }^{1} \quad$ Rohit Madhurkar $^{1} \quad$ Krishna Shama Rao $^{2} \quad$ Bibin Sebastian $^{1} \quad$ M. C. Uthappa
}

1Department of Intervention Radiology and Intervention Oncology, BGS Gleneagles Global Hospital, Bangalore, Karnataka, India

2Department of Craniofacial Surgery, BGS Gleneagles Global

Hospital, Bangalore, Karnataka, India

J Clin Interv Radiol ISVIR 2018;2:121-125

Cherubism is an autosomal dominant condition, first described by Jones in three siblings who presented with a fullness of the cheeks and enlargement of the jaws. ${ }^{1}$ The characteristic appearance closely resembled the Renaissance cherubs inspiring Jones to name it as cherubism., ${ }^{2,3}$ The condition is a fibro-osseous dysplasia characterized by painless symmetrical enlargement of the jaws. The mean age at the time of presentation is 7 years with a range of 12 months to 14 years. ${ }^{4}$ The condition has a $100 \%$ penetrance in males and 50 to $70 \%$ in females. ${ }^{5}$ In this article, we describe the role of angiography and embolization for a rare hypervascular variant of cherubism prior to surgical therapy.

\section{Case Report}

A 9-year-old girl presented with progressive, painless enlargement of both the cheeks. The symptoms were first observed at the age of 4 years. There was no associated
Address for correspondence Soumil Singhal, MD Radiodignosis, Fellow in Intervention Radiology, Department of Intervention Radiology and Intervention Oncology, BGS Gleneagles Global Hospital, Kengeri, Bangalore 560060, Karnataka, India (e-mail: drsoumilsinghal75@gmail.com).

difficulty in breathing or swallowing. However, the parents observed snoring in the last year of presentation. There was no history of similar symptoms in any of the family members. On examination, the swelling was noted to involve the bilateral maxilla and mandible. There was proptosis. Intraoral examination showed displaced and missing teeth. Laboratory evaluation was unremarkable with normal coagulation profile. A computed tomographic (CT) angiography of the head and neck demonstrated a diffuse expansile bone lesion involving the bilateral maxilla and mandible with a soap bubble pattern and cortical thinning. The lesion involved the mandibular condyles and pushed the orbital floor superiorly with associated narrowing of the superior orbital fissure and pterygopalatine fossa (-Fig. 1). On the angiographic phase, the soft tissue component within the lesion showed avid enhancement with multiple arterial feeders from bilateral facial and internal maxillary arteries. No arterial feeders were seen arising from the internal carotid arteries ( - Fig. 2 ).
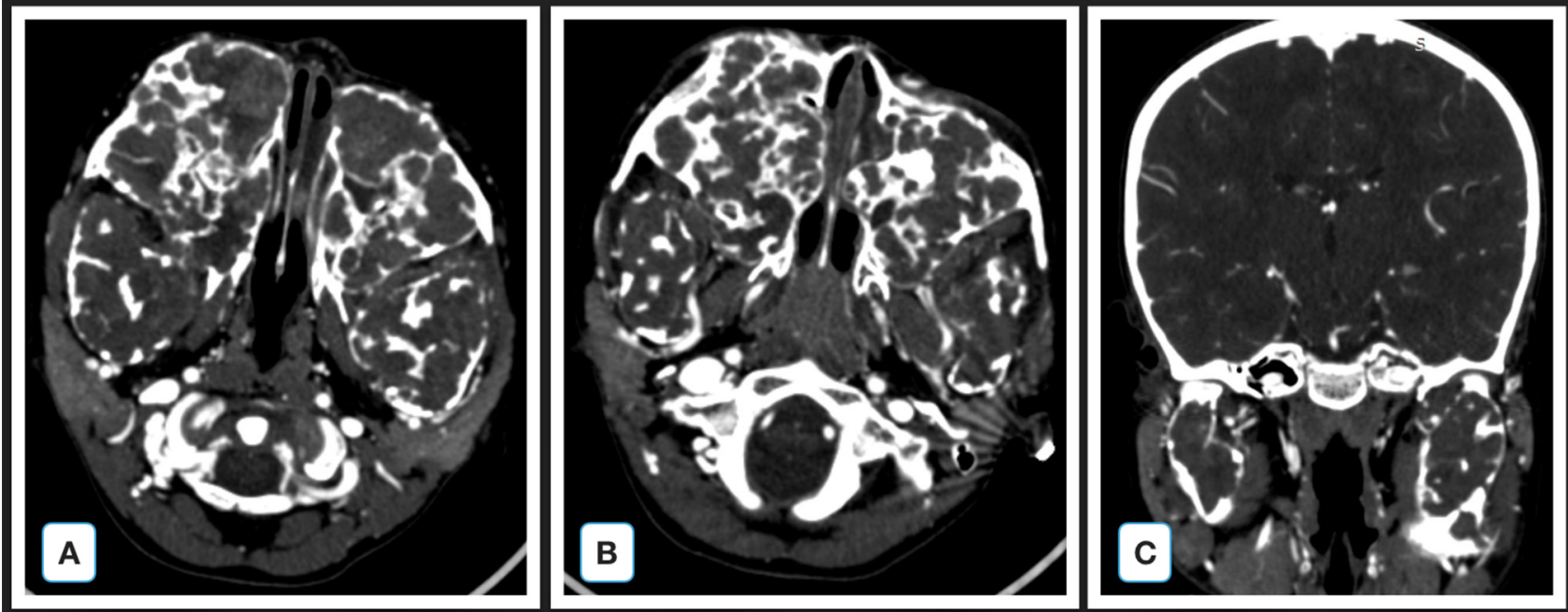

Fig. 1 Contrast-enhanced CT. (A, B) Axial sections. (C) Coronal reformat image showing classic expansile lesion with soap bubble pattern involving both the maxilla and mandible with soft tissue enhancement. (C) Bilateral condylar involvement.

received

April 6, 2018

accepted after revision

May 24, 2018

published online

July 31,2018
DOI https://doi.org/

10.1055/s-0038-1666965

ISSN 2457-0214.
Copyright $@ 2018$ by Indian Society of Vascular and Interventional Radiology
License terms

() (1) $\Theta \circledast$ 


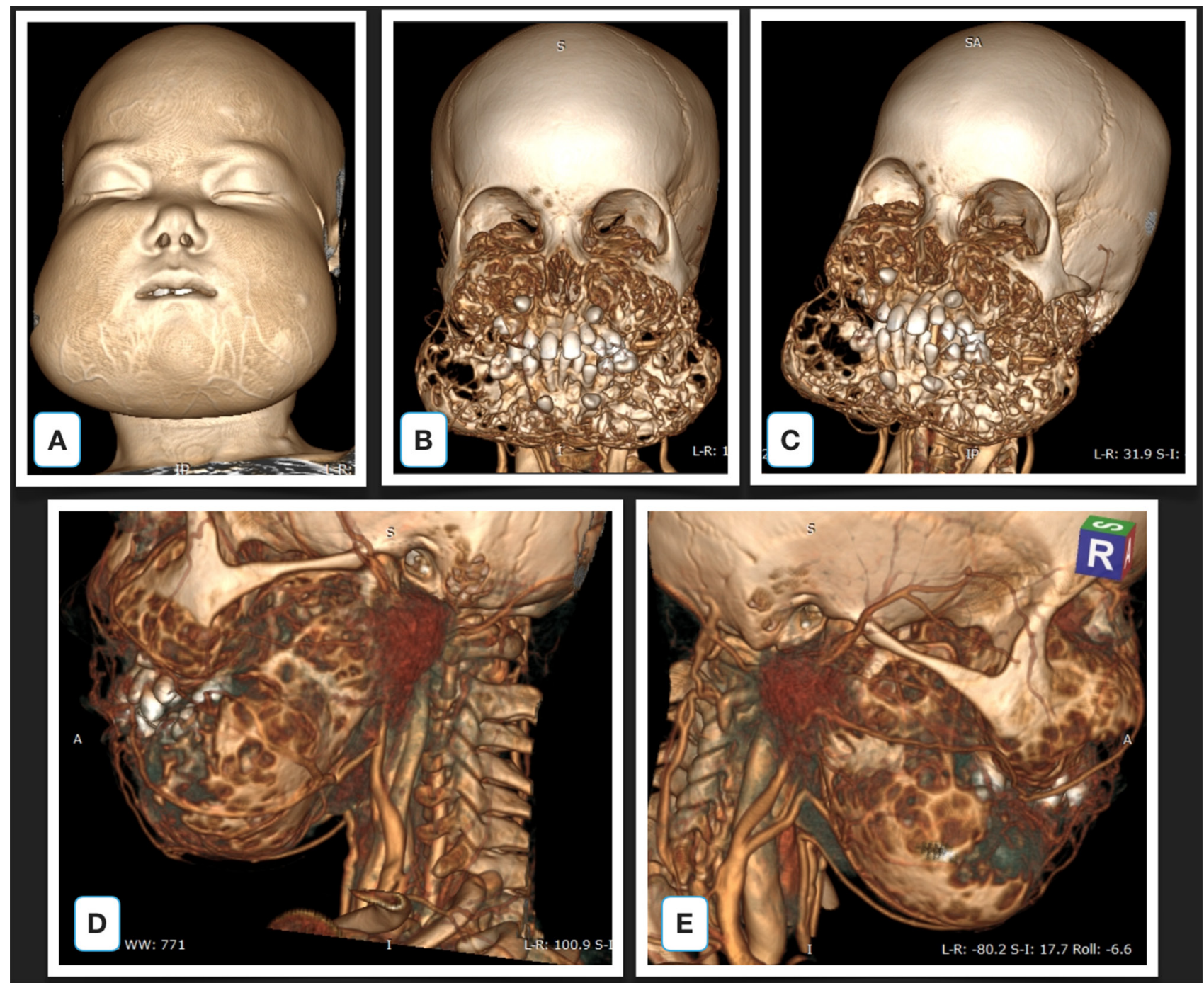

Fig. 2 Volume-rendered images. (A-C) Expansile lesion with soap bubble pattern involving both maxilla and mandible. (D, E) Arterial feeders to the lesion.

The patient was planned for a two-stage surgical correction. Stage 1 included a multidisciplinary approach with the interventional radiology team for presurgical embolization followed by surgical curettage. Stage 2 was cosmetic recontouring of the jaw after 6 months of stage 1 treatment.

Preoperative embolization was performed under general anesthesia. Through a right femoral arterial access, bilateral common carotid and selective external carotid angiography was performed. The bony lesion was supplied by multiple arterial feeders from the branches of the right internal maxillary artery (both the superior and inferior alveolar arteries), left internal maxillary artery (superior alveolar branches), and bilateral facial arteries. There were no arterial feeders from the internal carotid artery. Angiographic findings included enlarged arterial branches and a tumor-like contrast retaining blush in the late capillary phase. Each arterial branch supplying the hypervascular areas of the lesion was superselectively catheterized with a 2.7F microcatheter (Progreat, Terumo) and embolized to stasis using 300 to $500 \mu \mathrm{m}$ polyvinyl alcohol microspheres 


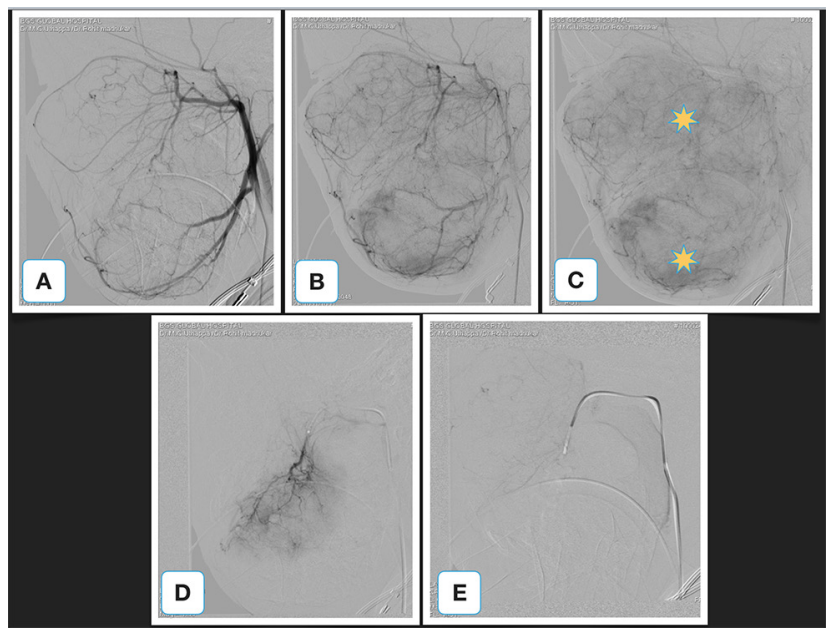

Fig. 3 External carotid angiography. (A-C) Contrast blush of the bony lesion (best seen on C [yellow star]). (D) Selective injection of superior alveolar artery with contrast blush. (E) Postembolization image showing absence of contrast blush.

(Cook Medical). Postembolization angiography showed stasis of flow to the lesion with no new feeders from either the internal or external carotid arteries (-Fig. 3). Postembolization, the patient underwent surgical curettage on day 2 (-Fig. 4). The surgery went well with no hemodynamic complications and very minimal blood loss $(50 \mathrm{~mL})$. The patient continues to do well ( - Fig. 5) and is on schedule for cosmetic recontouring surgery.

\section{Discussion}

Cherubism is a rare hereditary fibro-osseous dysplasia characterized by bone degradation and fibrous replacement. The World Health Organization (WHO) classifies cherubism as a non-neoplastic tumor of the mandible. ${ }^{6,7}$ Based on the radiographic location of the lesion in the jaw, Seward and Hankey has proposed a grading system ${ }^{8}$ : grade I-involvement of bilateral mandibular molar regions and ascending rami, mandible body, or mentis; grade II-involvement of bilateral maxillary tuberosities (in addition to grade 1 lesions) and diffuse mandibular involvement; grade III-massive involvement of the entire maxilla and mandible, except the condyles; grade IV-involvement of both the jaws, including the condyles. ${ }^{8}$ The patient in our study had a grade IV lesion that is considered to be a rare presentation. The lesion is even rarer because of its high vascularity, and according to our knowledge, only four cases of such similar highly vascular cherubism have been reported. ${ }^{9-12}$

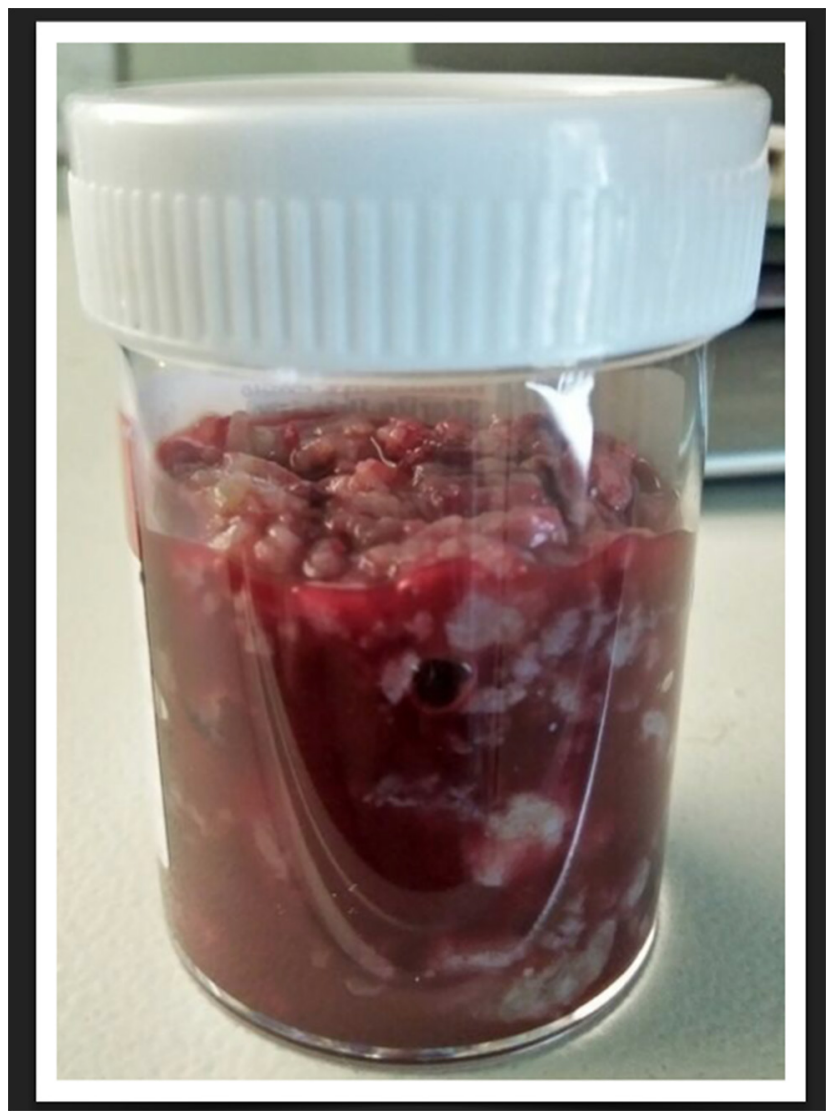

Fig. 4 Postcurettage material.

The treatment options for cherubism include conservative management and surgical management. Surgical management includes vigorous and repeated curettage and aesthetic correction surgery. ${ }^{13}$ Removal of the fibrotic component usually initiates ossification ${ }^{14}$; however, it can provoke postoperative enlargement, rapid recurrence, and diffuse bleeding. ${ }^{5.15}$ Because of the vascular nature of the lesion, bleeding can be profuse ranging from approximately 600 to $1,300 \mathrm{cc} .^{10,15,16}$ Surgical management is necessary in more aggressive cases to reduce facial deformities and progression of condition after puberty. ${ }^{17}$ Preoperative embolization of hypervascular cherubism reduces significant blood loss during surgical curettage. Polyvinyl alcohol (PVA) particles provide permanent effect due to adhesion to the vessel walls, causing stagnation of flow. This results in secondary focal angionecrosis and inflammatory reaction; 300 to $500 \mu \mathrm{m}$ are considered to prevent nontargeted embolization. According to our knowledge, preoperative 


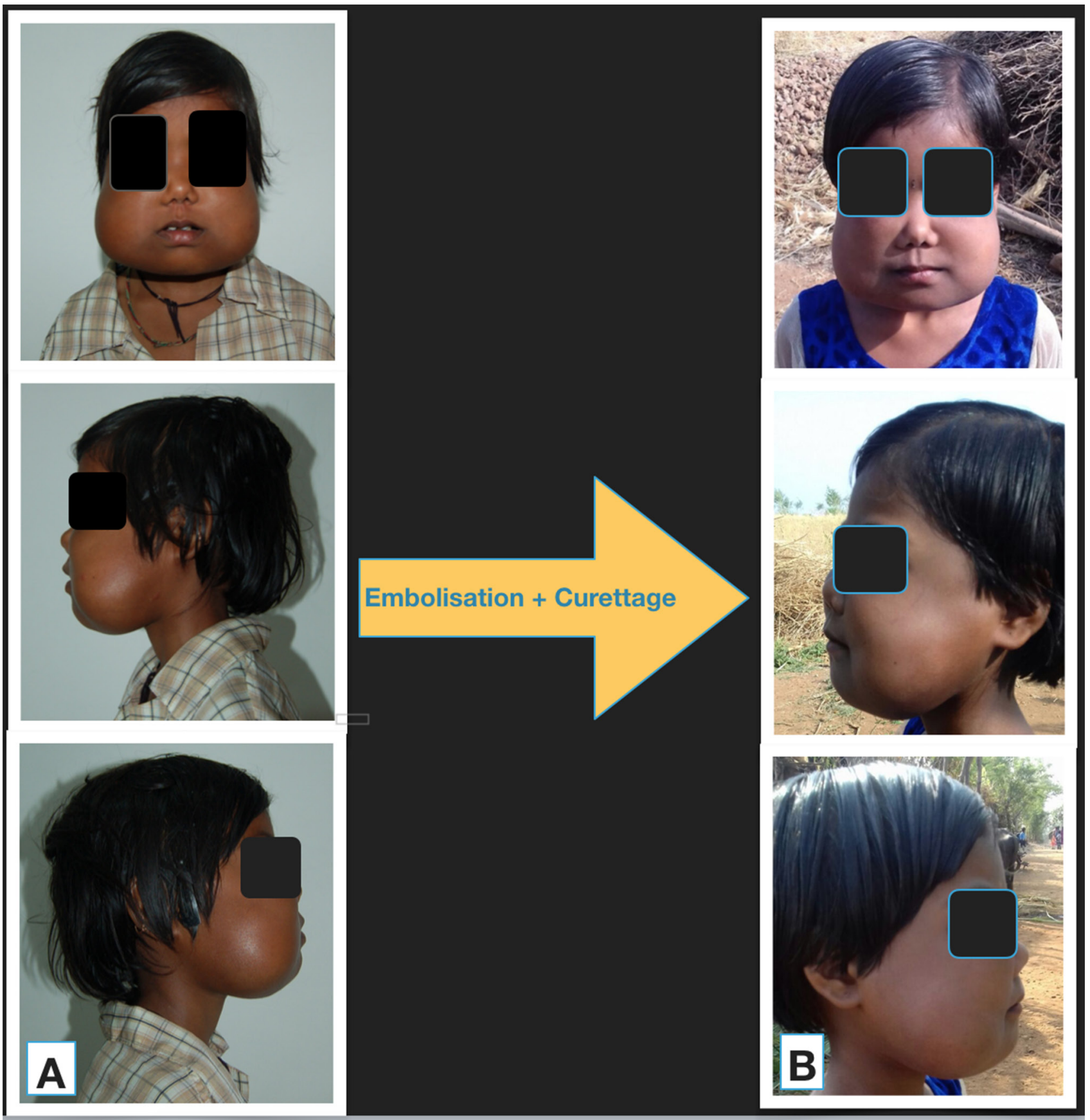

Fig. 5 Photographs comparing pre- and postembolization + curettage taken 2 months apart.

embolization has been reported only twice. ${ }^{12,18}$ Our case showed a significantly reduced blood loss $(\sim 50 \mathrm{~mL})$ when compared with that reported in the literature. ${ }^{12}$

\section{Conclusion}

Cherubism is a rare disease affecting the mandible and maxillary bones. Treatment is main surgical with curettage and reconstructive surgery. Preoperative embolization of hypervascular variants of cherubism helps reduce blood loss during surgical curettage.

\section{References}

1 Jones WA. Familial multilocular cystic disease of the jaws. Am J Cancer 1933;17(4):946-950

2 Waldron CA. Bone pathology. In: Neville BW, Damm DD, Allen $\mathrm{CM}$, et al, eds. Oral and Maxillofacial Pathology. Philadelphia, PA; Saunders; 1995:456-458

3 Kalantar Motamedi MH. Treatment of cherubism with locally aggressive behavior presenting in adulthood: report of four cases and a proposed new grading system. J Oral Maxillofac Surg 1998;56(11):1336-1342

4 Riefkohl R, Georgiade GS, Georgiade NG. Cherubism. Ann Plast Surg 1985;14(1):85-90 
5 Zachariades N, Papanicolaou S, Xypolyta A, Constantinidis I. Cherubism. Int J Oral Surg 1985;14(2):138-145

6 Yamaguchi T, Dorfman HD, Eisig S. Cherubism: clinicopathologic features. Skeletal Radiol 1999;28(6):350-353

7 Regezi JA, Sciubba J. Oral Pathology: Clinical-Pathologic Correlations. 2nd ed. Philadelphia, PA: Saunders; 1993;345-354

8 Seward GR, Hankey GT. Cherubism. Oral Surg Oral Med Oral Pathol 1957;10(9):952-974

9 Brannin DE, Christensen RO. Bilateral giant cell tumors of the mandible in siblings; report of cases. J Oral Surg (Chic) 1954;12(3):247-251

10 Hamner JE III, Ketcham AS. Cherubism: an analysis of treatment. Cancer 1969;23(5):1133-1143

11 Khosla VM, Korobkin M. Cherubism. Am J Dis Child 1970; 120(5):458-461

12 Koury ME, Stella JP, Epker BN. Vascular transformation in cherubism. Oral Surg Oral Med Oral Pathol 1993;76(1):20-27
13 Meng XM, Yu SF, Yu GY. Clinicopathologic study of 24 cases of cherubism. Int J Oral Maxillofac Surg 2005;34(4):350-356

14 Kaugars GE, Niamtu J III, Svirsky JA. Cherubism: diagnosis, treatment, and comparison with central giant cell granulomas and giant cell tumors. Oral Surg Oral Med Oral Pathol 1992;73(3):369-374

15 Topazian RG, Costich ER. Familial fibrous dysplasia of the jaws (cherubism): report of a case. J Oral Surg 1965;23:559-568

16 Lannon DA, Earley MJ. Cherubism and its charlatans. Br J Plast Surg 2001;54(8):708-711

17 Hitomi G, Nishide N, Mitsui K. Cherubism: diagnostic imaging and review of the literature in Japan. Oral Surg Oral Med Oral Pathol Oral Radiol Endod 1996;81(5):623-628

18 Henry F, Testelin S, Gauvin AC, Poirier J, Henry E. [Cherubism: the value of imaging and preoperative embolization] [in French] J Radiol 2003;84(11 Pt 1):1774-1778 